\title{
Kultura szkoły versus klimat szkoły
}

\begin{abstract}
The article attempts to analyse the notions of school culture and school climate as well as their definitions, scopes and the applied research approaches. Although such activities have been undertaken and presented both in English and German literature, they have failed to constitute a separate field of analysis in Poland and as such, have been merely addressed on the margins of other problems. In this article, the author points out the positions of researchers who have identified the need to clarify the separate identity of the notions and for this purpose, to adopt appropriate research approaches, often leading, as the author attempts to illustrate, to diverse conclusions.
\end{abstract}

\section{Keywords:}

school culture, school climate, school development, school efficiency

Pomimo wczesnej konceptualizacji kategorii kultury szkoły i klimatu szkoły istnieje wiele nieporozumień widocznych już na poziomie definiowania i dookreślania zakresów pojęciowych (Denison,1996). Chociaż zarówno klimat, jak i kultura szkoły były i są uznawane za kluczowe aspekty poprawy szkolnej efektywności (rozwoju szkoły), to terminy te często są mylone i stosowane zamiennie. Zjawisko to nasiliła się od lat 90 . XX wieku, gdy badania efektywności szkoły zaczęły się

1 Inetta Nowosad, Zakład Pedagogiki Szkolnej, Wydział Pedagogiki, Psychologii i Socjologii, Uniwersytet Zielonogórski, Polska, inettanowosad@wp.pl. 
intensywnie rozwijać, poszerzając obszar analiz o kulturę i klimat jako kluczowy aspekt zmiany (Nowosad, 2017, s. 135-138).

Zdarza się, że wyłaniająca się niejednoznaczność i nieostrość rozumienia prowadzi do pokrywania się znaczenia lub nawet sprzeczności, co tylko komplikuje wyznaczenie procesu badawczego i porównywanie uzyskanych wyników. Zwraca to uwagę na konieczność dookreślenia przedmiotu badań, bowiem stosowanie w nauce interpretacji w sposób dowolny i bezkrytyczny nie tylko pozbawia go przejrzystości, ale także jest niedopuszczalne. Potrzebne zatem wydaje się rozdzielenie istoty obu pojęć i wskazanie różnic w interpretacji oraz przyjęcie już „na wejściu” założenia o umowności zastosowania takiego podziału.

\section{WYBRANE UJĘCIA DEFINICYJNE}

W podejmowanych próbach dookreślenia istoty kultury szkoły badacze zwracają uwagę na nieuchwytny, niematerialny charakter konstrukcji znaczeniowej samego przedmiotu, co utrudnia zdefiniowanie lub bezpośrednie zaobserwowanie (Halsall, 1998; Stoll, Fink, 1996). Nawet w powszechnie akceptowanych i często przywoływanych w literaturze definicjach ta niejednoznaczność, ale też efemeryczność często jest utrwalana przez przyjmowanie niespecyficznych, abstrakcyjnych terminów i tylko przyczynia się do dużej rozpiętości istniejących ujęć. Od bardzo ogólnych - można by rzec - metaforycznych - po próby bardziej usystematyzowanego podejścia.

- To hologram, „w którym w każdym miejscu kliszy zapisana jest informacja o całym przedmiocie i jego obraz można odtworzyć nawet z małego fragmentu” (Cameron, Quinn, 2003, s. 25).

- Kultura szkoły to „żywy organizm” o indywidualnej historii, tradycji, funkcjonujący w specyficznym środowisku z unikatową zdolnością do tworzenia własnego losu (Handy, 1997, s. 117-127).

- „Sposób, w jaki my to tutaj robimy” (Bjerke, 2004).

- „To zbiorowe zaprogramowanie umysłu, które odróżnia członków jednej organizacji od drugiej” (Hofstede, 2001, s. 5).

- „Kulturę szkoły tworzą przede wszystkim normy i wartości uczestników [...] Każda organizacja ma określony, charakterystyczny dla siebie system wartości zwany też kulturą organizacyjną. Stanowi ona swoiste jądro działalności organizacji, z którego wynikają niemal wszystkie posunięcia strategiczne” (Peters, Waterman, za: Furmanik, 2012, s. 116). 
- Kulturą szkoły można określić wiodące przekonania i wartości widoczne w sposobie funkcjonowania szkoły (Fullan, 2007).

- Kultura szkoły jest „szczególną wielowymiarową przestrzenią rozwoju osoby i kształtowania ładu zbiorowego, jest ogółem przekonań, poglądów, postaw i relacji oraz pisanych i niepisanych zasad, które kształtują każdy aspekt funkcjonowania szkoły jako instytucji, organizacji i wspólnoty” (Ward, Burke, za: Czerepaniak-Walczak, 2018, s. 80).

Mimo różnych interpretacji samej kategorii kultury szkoły istnieje zgodność, że jej wartość poznawcza wynika z całościowego ujęcia różnych aspektów szkolnej codzienności i jest pomocna w poznaniu i zrozumieniu natury życia i edukacji w szkołach (Wiater, 2009, s. 354).

Wśród ujęć definiujących istotę klimatu szkolnego można odnaleźć następujące:

- Klimat jako jakość i cechy życia szkolnego, łącznie ze wsparciem w procesach nauczania i uczenia się. W przyjętym ujęciu zawierają się cele, wartości, relacje interpersonalne, formalne struktury organizacyjne i praktyka organizacyjna (Clifford, Menon, Gangi, Condon, Hornung, 2012, s. 3).

- Klimat szkolny to poczucie szkoły jako wspólnoty, z uwzględnieniem „jakości relacji społecznych między członkami społeczności szkolnej” (Ding, Liu, Berkowitz, 2011, s. 243).

- Klimat szkolny odnosi się do jakości i charakteru życia szkolnego. Wynika z doświadczania wzorców przyjętych przez uczniów, rodziców i personelu szkoły w szkolnej codzienności. Odzwierciedla normy, cele, wartości, interpersonalne relacje, praktyki nauczania i uczenia się oraz organizacyjne struktury (National School Climate Center, 2014).

- Klimat szkolny opiera się na wzorcach doświadczeń ludzi związanych z życiem szkolnym i odzwierciedla normy, cele, wartości, relacje międzyludzkie, nauczanie, a także praktyki uczenia się i struktury organizacyjne. Zrównoważony, pozytywny klimat szkolny sprzyja rozwojowi młodzieży, jest niezbędny w produktywnym życiu i przyczynia się do poczucia satysfakcji z życia w demokratycznym społeczeństwie. Klimat obejmuje normy, wartości i oczekiwania, które tworzą u ludzi poczucie bezpieczeństwa społecznego, emocjonalnego i fizycznego. W pozytywnym klimacie szkoły ludzie są zaangażowani i szanowani (Łukasik, 2010, s. 51-59). Uczniowie, ich rodziny i nauczyciele pracują razem nad rozwojem szkolnego życia w realizacji wspólnej wizji szkoły. Nauczyciele kształtują i pielęgnują postawy, które podkreślają korzyści i satysfakcję z nauki. Każdy członek 
szkolnej społeczności przyczynia się do funkcjonowania szkoły (National School Climate Council, 2007).

\section{TREŚĆ I ZAKRES KATEGORII KULTURY I KLIMATU SZKOŁY}

Mieke Van Houtte (2011), stawiając prowokacyjne pytanie Climate or Culture? (Klimat czy kultura?) oraz La Tefy Schoen i Charles Teddie (2008), podejmując się opracowania nowego modelu kultury szkoły, po przeanalizowaniu literatury przedmiotu zauważyli uderzające podobieństwa w traktowaniu kultury szkoły, kultury organizacyjnej i klimatu szkoły, mimo, że są z nim powiązane różne dyscypliny naukowe i tradycje badawcze. Swoje analizy ukierunkowali pytaniami: czy kultura szkoły i klimat szkoły to pojęcia zasadniczo od siebie różne? Czy może w swej istocie wystarczająco bliskie? Zatem, czy są to pojęcia tożsame? Czy może jedno zawiera się drugim? Tylko które?

Prób rozdzielenia pojęć kultury i klimatu szkoły i uwzględnienia ich wzajemnych zakresów pojęciowych było więcej, jednak wnioski ukazują diametralnie odmienne stanowiska², co tylko umacnia potrzebę dookreślenia pola problemowego i wskazania istniejących związków i zależności. Tu opinie naukowców są jednak podzielone. $Z$ jednej strony (i bez przecinka), klimat jest uznawany za obejmujący kulturę z uwzględnieniem warunku, że dotyczy obrazu szkoły jako całości. Przykładowo Rada Narodowa ds. Klimatu Szkoły sugeruje, że kultura jest podzbiorem klimatu w szkole. W uzasadnieniu wskazano, iż kultura szkoły odnosi się do tych cech, które można w szkole zmienić przez świadomy wysiłek ludzi w organizacji bez potrzeby żadnych fizycznie widocznych zmian lub zmian w strukturze organizacyjnej. Wskazywane cechy są tu równoznaczne z pojmowaniem kultury szkoły i obejmują wartości oraz normy struktury organizacji (w tym misję szkoły) oraz sposoby ich aktualizacji poprzez relacje (U.S. Department of Education, 2007). Podobnie Ann Higgins-D’Alessandro oraz Devyani Sadh (1998) sugerują, że kultura szkolna powinna odnosić się

2 Najczęściej badacze powołują się na trzy naukowo opracowane procedury badań istoty i zakresów pojęć kultury i klimatu szkoły: A. Higgins-D’Alessandro, D. Sadh (1988). The dimensions and measurement of school culture: Understanding school culture as the basis for school reform. International Journal of Educational Research, 27(7), s. 553-556; L.T. Schoen, C. Teddlie (2008). A new model of school culture: a response to a call for conceptual clarity. School Effectiveness and School Improvement, 19(2), s. 129-153; U.S. Department of Education, Office of Safe and Drug-Free Schools (2007). Mobilizing for evidence-based character education. Washington, http:// www2.ed.gov/programs/charactered/mobilizing.pdf. 
do norm i relacji w szkole, które z kolei informują i kształtują zachowanie członków społeczności. Ich zdaniem kultura szkolna jest aktywnym składnikiem klimatu szkoły, który powoduje zmiany w szkole. W tym ujęciu kategoria kultury szkoły jest preferowana do badania struktur poznawczych szkoły (van Houtte, 2005, s. 71).

Równie szerokie ujęcie w rozumieniu klimatu szkoły można odnaleźć w jego interpretacji jako „serca i duszy” szkoły (Freiberg, 1999, s. 11) czy też jako całości: atmosfery, kultury i zasobów w społecznej sieci szkolnych relacji” (Loukas, Murphy, 2007, s. 293). Również Mark Hanson (2003) oraz Robert Owens (2001) uznali, że kultura jest składnikiem klimatu. Naukowcy w wyjaśnieniu fenomenu przyjmowania kultury szkoły jako komponentu klimatu odnoszą się do argumentacji Renato Taguiri z 1968 roku i jego przełomowej pracy nad kulturą z punktu widzenia klimatu będącego swoistą kombinacją kultury, środowiska, ekologii i organizacji. Taguiri uznał klimat szkoły za kategorię szerszą, oddającą wielowymiarowy konstrukt, w którego skład wchodzą: „ekologia środowiska/otoczenie fizyczne; charakterystyka jednostek i grup partycypujących w danej organizacji; system społeczny/relacje miedzy jednostkami i grupami danej organizacji; kultura/ przekonania, wartości i znaczenia” (Tłuściak-Deliowska, 2015, s. 77). W efekcie „to klimat zwiera w sobie kulturę szkoły, ale też jest od niej zależny” (Tłuściak-Deliowska, 2015). Mimo wczesnej popularności tych założeń, aktualna sytuacja pozostaje nierozstrzygnięta, co obrazują istniejące różnice i niezgodność badaczy w rozdzieleniu kategorii klimatu i kultury szkoły. Równie zasadne i uargumentowane w sposób naukowy są bowiem inne poglądy wskazujące i dowodzące, że to klimat jest częścią kultury szkoły (Poole, 1985). Jeszcze inne podejście zaproponowali Richard Burton i Borge Obel (1998, 2004) dowodząc, że klimat i kultura są od siebie niezależne.

Ujęcia definicyjne kultury i klimatu szkoły, choć wydają się bardzo podobne, różnią się jednak pod względem bardzo ważnej kwestii. Klimat jest świadomie postrzegany przez aktorów szkolnej rzeczywistości i może być opisywany przez panujące wartości organizacji, podczas gdy kultura jest podstawą tych wartości, stanowiących dla społeczności wszechobecny kontekst dla wszystkiego, co robi i myśli. Kultura obejmuje więcej niż opis klimatu w organizacji. Odnosi się do wartości, norm i artefaktów, klimat zaś do ich indywidualnego rozpatrzenia przez członków organizacji. Ponadto można wykazać, że badania klimatu mogą być włączone do koncepcji kultury, podczas gdy nie jest tak w przypadku odwrotnym (Schoen, Teddlie, 2008, s. 137). Kultura wyraża się zatem w klimacie, a postrzegany klimat organizacyjny można rozumieć jako aspekt kultury. Również Oswald Neuberger i Ain Kompa (1987) udowadniają, że 
kultura organizacji przejawia się w klimacie. W ten sposób wystarczy uchwycić klimat, by zrozumieć kulturę.

Konieczność szerszego rozumienia kultury szkoły uzasadniają Stephen Stolp i Stuart C Smith (1995, s. 15-17), definiując „klimat” jako podzielane przez większość ludzi postrzeganie organizacji lub komórki tej organizacji, zaś „kulturę” jako założenia, wartości i normy, które kształtują tożsamość organizacji i specyficzne standardy stosowanych praktyk. W efekcie kultura warunkuje sposób odczuwania organizacji przez jej członków. Zatem klimat odnosi się w tym przypadku do wrażeń, odczuć, oczekiwań reprezentowanych przez daną społeczność i jest jednym ze składników kultury szkoły.

Jeśli badacze przyjmują podejście systemowe oraz normy i wartości jako ramy określające zachowanie, to konieczne jest użycie terminu „kultura”, a nie „klimat”. Kultura bowiem poza klimatem składa się z różnych aspektów, które określają i odzwierciedlają organizację jako całość. Kultura jest w organizacji przeżywana i nauczana, udostępniana, wdrażana i rejestrowana. Zawiera, w przeciwieństwie do klimatu, aspekty normatywne i ewaluacyjne oraz podkreśla funkcjonalność organizacji. Niestety istniejące na tym polu analizy nie dostarczają jednoznacznego obrazu kultury organizacyjnej, która jest trudna do uchwycenia, bowiem ściśle powiązana z przyjętym podejściem badawczym. Dorobek badawczy Scheina na polu kultury organizacyjnej wydaje się najlepiej wyjaśniać, w jaki sposób kultura i klimat mogą być powiązane (tabela 1). Schoen i Teddlie (2008, s. 138) podkreślają, że właściwie nie są to oddzielne struktury, ale elementy jednego szerszego konstruktu, które badano osobno, na różne sposoby, przez różne zespoły badawcze. Jak zauważają: „im więcej badaliśmy literatury dotyczącej kultury i klimatu, tym bardziej ta możliwość wydawała się nam prawdopodobnym wyjaśnieniem pozornego nakładania się lub rozmycia tych terminów”.

Tabela 1. Klimat szkoły jako poziom kultury szkoły

\begin{tabular}{lll}
\hline Poziomy kultury szkoły & & Poziomy kultury organizacyjnej Scheina \\
\hline Symbole kultury & $\rightarrow$ & Artefakty \\
\hline Klimat szkoły & $\rightarrow$ & Powszechne przekonania \\
\hline Kultura szkoły & $\rightarrow$ & Podstawowe założenia \\
\hline
\end{tabular}

Źródło: Opracowanie własne na podstawie: L.T. Schoen, C Teddlie (2008). A new model of school culture: a response to a call for conceptual clarity. School Effectiveness and School Improvement, 19(2), s. 138. 


\title{
3. KULTURA SZKOŁY I KLIMAT SZKOŁY. PODOBIEŃSTWA I RÓŻNICE
}

J. Prosser (1999, s. 5) zwraca uwagę, że jednym z powodów istniejącej różnorodności w definiowaniu kultury organizacyjnej szkoły jest zależność od specjalizacji badacza.

\begin{abstract}
„Klimat szkoły jest pojęciem częściej stosowanym przez badaczy klasy szkolnej, kultura organizacyjna szkoły przez badaczy jakościowego rozwoju szkoły i socjologów edukacji, zaś etos, atmosfera i tożsamość najczęściej jest przyjmowana przez psychologów, którzy stosują wybrane określenia do opisu eterycznych przymiotów szkoły. Inna z sugestii, eksponuje rangę geograficznej lokalizacji badacza. W tym ujęciu klimat szkoły jest preferowany w Stanach Zjednoczonych, podczas gdy w Szkocji częściej można się spotkać z pojęciem etosu szkoły” (za: Szczecińska, 2010, s. 145).
\end{abstract}

W wyjaśnieniu głównej przyczyny istniejących nieporozumień i podobieństwa interpretacji dotyczących analizowanych tu kategorii badacze zwracają uwagę, że o ile we wczesnych badaniach klimatu i kultury wskazanie różnic wydaje się stosunkowo proste, o tyle współcześnie jest to zadanie o wiele bardziej skomplikowane. Najprościej ujęto to w słowach: „,bez względu na to, czym jest, kultura to nie klimat”. Bowiem ,jednym ze sposobów zrozumienia kultury jest zrozumienie tego, czego nie widać” (Schwartz, Davis, 1981, s. 32). Przyjęto, że badanie kultury wymaga jakościowych metod badawczych, a klimatu - metod ilościowych. Daniel Denison (1996, s. 621) zwraca uwagę, że we wczesnej fazie było to powszechne stanowisko. Jeśli badacz miał przy sobie notatki terenowe, wypowiedzi lub opowiadania i przedstawił dane w sposób jakościowy dowodzeniu swoich założeń, badał kulturę. Jeśli zaś wypełniał kwestionariusze oraz przedstawiał dane ilościowe - badał klimat.

Współcześnie tendencja ta wydaje się wciąż istotna. Można przyjąć założenie, że pojecie klimatu jest stosowane bardziej konsekwentnie przez osoby angażujące się w badania ilościowe, jak w przypadku naukowców zajmujących się efektywnością szkoły. Podczas gdy „kultura” pojawia się częściej u tych, którzy podejmują się badań jakościowych i analizują szkołę (edukację) z perspektywy antropologicznej. Próbę wykazania różnic na tym polu podjął się Robert G. Owens (2001). W swoich pracach podaje, że klimat szkolny zazwyczaj wiąże się z analizami ilościowymi, a kultura szkolna z jakościowymi, choć jednocześnie przestrzega, że kultura szkoły jest czymś więcej niż tylko szkolnymi wartościami badanymi jakościowo. Niestety taki rozdział okazuje się mało wystarczający 
w przypadku, kiedy to badacze nakładają na siebie niektóre wartości badanych przedmiotów i czynią to zarówno z perspektywy organizacyjnej - efektywności procesów wewnątrzszkolnych (Levine, Lezotte, 1990; Teddlie, Stringfield, 1993), jak i orientacji antropologicznej (Deal, Kennedy, 1982; Deal, Peterson, 1999; Sarason, 1971, 1990). Schoen i Teddlie (2008, s. 131-132, 135) wskazują na jeszcze inny problem. W definicjach klimatu szkolnego i kultury szkoły występuje znaczne pokrywanie się treści, nawet w ramach tej samej dyscypliny i orientacji badawczej (por. tabela 2).

Tabela 2. Obszary konwergencji w dziedzinie kultury i klimatu

\begin{tabular}{ll}
\hline $\begin{array}{l}\text { Obszary } \\
\text { konwergencji }\end{array}$ & Przykłady \\
\hline - Definiowanie & - Skupiają się na środowisku jako całości, zbiorowo określonym, \\
zjawiska & społecznym kontekście \\
- Główne problemy & - Wspólny dylemat: kontekst powstaje w wyniku interakcji, ale \\
teoretyczne & kontekst określa interakcję \\
- Treść i substancja & - Definicja domeny jest bardzo różna w zależności od indywidualne- \\
- Epistemologia & go badacza \\
i metody & Bardzo pojemne obszary analiz \\
- Podstawy teore- & Dynamika między całością a częścią \\
tyczne & - wpływy vs. analiza holistyczna \\
& - subkultury vs. kultura jednolita \\
& Duże nakładanie się wymiarów w badaniach ilościowych kultury \\
& i badaniach klimatu \\
& Niedawne pojawienie się badań ilościowych nad kulturą i strategii \\
& jakościowej w badaniach klimatu \\
& Geneza badań nad kulturą leży w konstruktywizmie społecznym; \\
& geneza badań klimatu - w teorii pola Lewina. Wiele ostatnich \\
& badań skrzyżowało je lub łączyło tradycje \\
\hline
\end{tabular}

Źródło: Opracowanie własne na podstawie: D.R. Denison (1996). What is the Difference between Organizational Culture and Organizational Climate? A Native's Point of View on a Decade of Paradigm Wars. Academy of Management Review, 3(21), s. 627.

W dalszej części swojego wywodu Schoen i Teddlie (2008) wyjaśniają, że określenie związków i zależności pomiędzy kulturą a klimatem szkoły pozostawione było na marginesie zainteresowań badaczy, skupionych bardziej na identyfikacji przedmiotu i dookreślaniu definicji czy wskazywaniu aspektów obu konstruktów poznawczych. „Niewiele uwagi poświęcono zależnościom między elementami kultury, ponieważ wciąż próbowaliśmy zrozumieć dokładnie to, czym w ogóle jest kultura lub klimat”.

W odczytywaniu różnic obu kategorii, najczęściej zwraca się uwagę na prowadzenie badań w różnych dyscyplinach. Wayne K. Hoy i Cecil G. Miskel (1991) zauważyli, że klimat szkoły czy też klimat organizacyjny jest zazwyczaj postrze- 
gany z perspektywy psychologicznej, natomiast kultura szkoły jest postrzegana z perspektywy antropologicznej. Jednakże, kontrargumentem może być stanowisko Jerome’a Freiberga (1999), który wskazał na zalety obu dyscyplin w badaniu klimatu szkoły, odnosząc się z uznaniem zarówno do tradycji psychologicznej z wykorzystaniem zestawów znormalizowanych narzędzi diagnostycznych umożliwiających pomiar szeregu zmiennych, jak i antropologicznej z wykorzystaniem źródeł, takich jak dokumenty szkolne, wywiady, pamiętniki, kroniki, rysunki uczniów, czasopisma dla nauczycieli i uczniów oraz filmy.

Inną akcentowaną próbą wyostrzenia pola problemowego obu terminów jest eksponowanie większej precyzji w identyfikowaniu kultury i klimatu szkoły z perspektywy teorii organizacji. Wówczas klimat szkoły jest najczęściej definiowany przez pryzmat warunków zachowania i zachodzących interakcji, zaś kultura szkoły - przez pryzmat istniejących w szkole wartości i norm (Heck,

Tabela 3. Związek między kulturą szkoły a klimatem szkoły

\begin{tabular}{|c|c|c|}
\hline Kryteria analizy & Kultura szkoły & Klimat szkoły \\
\hline $\begin{array}{l}\text { - Istota } \\
\text { - Treść } \\
\text { - Wytwór }\end{array}$ & $\begin{array}{l}\text { - Wartości i normy } \\
\text { - Założenia i ideologia } \\
\text { - Osobowość grupy }\end{array}$ & $\begin{array}{l}\text { - Determinanty zachowań i inte- } \\
\text { rakcje } \\
\text { - Postrzeganie zachowania } \\
\text { - Postawa lub nastrój grupy }\end{array}$ \\
\hline $\begin{array}{l}\text { - Funkcjonowanie } \\
\text { ludzi } \\
\text { - Możliwość odczu- } \\
\text { cia przez członków } \\
\text { - Dyscyplina } \\
\text { - Orientacja badaw- } \\
\text { cza } \\
\text { - Poziom abstrakcji } \\
\text { - Opisy i wyjaśnienia } \\
\text { - Impuls do zmiany } \\
\text { - Tempo zmiany }\end{array}$ & $\begin{array}{l}\text { Zapewnia stan umysłu } \\
\text { - Sposób, w jaki robimy tutaj } \\
\text { różne rzeczy } \\
\text { - Członkowie nie mogą jej po- } \\
\text { czuć, jest wszędzie wokół nich. } \\
\text { Jest ich częścią } \\
\text { - Antropologia i socjologia } \\
\text { - Jakościowa } \\
\text { - Abstrakcja } \\
\text { - Bardziej ogólne } \\
\text { - Określa, czy poprawa jest } \\
\text { - Zmożliwa } \\
\text { - Zmiana trwa wiele lat. Ewolucja }\end{array}$ & $\begin{array}{l}\text { Zapewnia (ograniczony) sposób } \\
\text { myślenia } \\
\text { - Sposób, w jaki się tutaj czujemy } \\
\text { - Członkowie mogą go poczuć, } \\
\text { będąc w szkole } \\
\text { - Psychologia i psychologia } \\
\text { społeczna } \\
\text { - Ilościowa } \\
\text { - Konkret } \\
\text { - Bardziej precyzyjne } \\
\text { - Pierwszy krok do poprawy } \\
\text { - Zmiany mogą następować sto- } \\
\text { sunkowo szybko. Elastyczność } \\
\text { zmian }\end{array}$ \\
\hline
\end{tabular}

Wspólne: istotny wskaźnik zmiany i poprawy szkoły

Źródło: Opracowanie własne na podstawie: S. Gruenert, School Culture, School Climate, https:// www.naesp.org/sites/default/files/resources/2/Principal/2008/M-Ap56.pdf; W.K. Hoy (1990). Organizational Climate and Culture: A Conceptual Analysis of the School Workplace. Journal of Educational and Psychological Consultation, 1(2), s. 149-168; W.K. Hoy i in. (1991). Open school/ Health school: measuring organizational climate. Sage Publications: Newbury Park; L.T. Schoen, C. Teddlie (2008). A new model of school culture: a response to a call for conceptual clarity. School Effectiveness and School Improvement, 19(2), s. 129-153. 
Marcoulides, 1996). Schoen i Teddlie zwrócili również uwagę, że o wiele częściej (choć nie jest to regułą) definicje klimatu są bardziej szczegółowe i jednoznaczne, podczas gdy ujęcia definicyjne kultury szkoły są bardziej ogólne i holistyczne. I w tym przypadku, swoje odkrycie uzasadniają przyjmowanymi przez naukowców orientacjami badawczymi, z których wyprowadzane są pojęcia.

Wspólne w tak zróżnicowanych perspektywach wydaje się jedno, a mianowicie łączenie przez badaczy (zwłaszcza współcześnie jest to zdominowane podejście) pojęć kultury szkolnej, klimatu szkoły lub klimatu organizacyjnego z efektywnością szkoły lub poprawą pracy szkoły (Łukasik, Pikuła, 2015, s. 78-92). Obie kategorie kultury i klimatu w badaniach szkoły zostały w większości aktualnych projektów uznane jako zmienne, które ostatecznie wpływają na osiągnięcia uczniów. W tej sytuacji Louise Stoll i Dean Fink zidentyfikowali kulturę szkolną i/lub klimat jako istotny aspekt procesu poprawy szkoły (1996). Niestety, przyjęcie takich wniosków może tylko komplikować rozdzielne ujmowanie interesujących nas tu kategorii.

\section{KONKLUZJE}

Bez wątpienia rozdział zakresów znaczeniowych kultury oraz klimatu szkoły jest umowny. Stanowi jedynie ramy poznawcze ułatwiające orientację na polu bardzo bogato reprezentowanych ujęć. W jednakowej mierze wyostrza pewne perspektywy, jak i je ogranicza. Jednakże mimo istniejących wątpliwości rozdział pojęć może być pomocny w określaniu przez badaczy przedmiotu badań, osadzając go odpowiednio w kulturze lub klimacie szkoły, co nie zwalnia z przyjęcia wybranej koncepcji teoretycznej.

\section{Bibliografia}

Bjerke, B. (2004). Kultura a style przywództwa. Kraków: Oficyna Ekonomiczna.

Burton, R.M., Obel, B. (1998). Strategic Organizational Diagnosis and Design: Developing Theory for Application. Dordrecht: Kluwer Academic Publishers.

Burton, R.M., Obel, B. (2004). Strategic Organizational Diagnosis and Design. The Dynamics of Fit. New York: Springer Science \& Business Media.

Cameron, K.S., Quinn, R.E. (2003). Kultura organizacyjna - diagnoza i zmiana. Model wartości konkurujących. Kraków: Oficyna Ekonomiczna.

Clifford, M. i in. (2012). Measuring school climate for gauging principal performance: A review of the validity and reliability of publicly accessible measures. American Institutes for Research, Washington. Pobrano z: http://www.air.org/files/school_climate2.pdf 
Czerepaniak-Walczak, M. (2018). Proces emancypacji kultury szkoły. Warszawa: Wolters Kluwer.

Deal, T.E., Kennedy, A. (1982). Corporate cultures: The rites and rituals of corporate life. Reading: Addison-Wesley.

Deal, T.E., Peterson, K. (1999). Shaping school culture: The heart of leadership. San Francisco: Jossey-Bass.

Denison, D.R. (1996). What is the Difference Between Organizational Culture and Organizational Climate? A Native's Point of View on a Decade of Paradigm Wars, Academy of Management Review, 21(3), s. 619-654.

Dernowska, U., Tłuściak-Deliowska, A. (2015). Kultura szkoły. Studium teoretyczno-empiryczne, Kraków: Impuls.

Ding, C. i in. (2011). The study of factor structure and reliability of an abbreviated school climate survey. Canadian Journal of School Psychology, 26, s. 241-256.

Fischer, D. (2009). Was ist Schulkultur und wie kann man sie entwickeln? W: M. Jäggle i in. (red.), Lebens. Werte. Schule: Religiöse Dimensionen in Schulkultur und Schulentwicklung. Lit Verlag: Wien.

Freiberg, J. (1999). School climate: Measuring and sustaining healthy learning environments. London: Falmer.

Fullan, M. (2007). The new meaning of educational change. New York: Teachers College Press.

Furmanik, M. (2012). Kultura organizacyjna w szkołach różnych krajów. Zarządzanie Publiczne, 1(21), s. 115-125.

Gruenert, S. (2000). Shaping a new school culture. Contemporary Education, 71(2), s. $14-18$.

Hall, G.E., Hord, S.M. (2015). Implementing Change: Patterns, Principles, and Potholes. Boston: Pearson.

Halsall, R. (1998). Teacher research and school improvement. Philadelphia: Open University Press.

Handy, Ch., Aitken, R. (1986). Understanding Schools as Organizations. Harmondswort: Penguin.

Handy, Ch. (1997). Schools for life and work. W: P. Mortimore, V. Little (red.), Living Education: Essays in Honour of John Tomilnson (s. 117-127). London: Paul Chapman Publishing.

Hanson, E.M. (2003). Educational management and organizational behavior. Boston: Allyn \& Bacon.

Heck, R.H., Marcoulides, G.A. (1996). School culture and performance: Testing the invariance of an organizational model. School Effectiveness and School Improvement, 7, s. 76-96.

Higgins-D’Alessandro, A., Sadh, D. (1998). The dimensions and measurement of school culture: Understanding school culture as the basis for school reform. International Journal of Educational Research, 27(7), s. 553-556.

Hofstede, G. (2001). Kultury i organizacje. Warszawa: PWN.

Hoy, W.K., Miskel, C.G. (1991). Educational administration: Theory, research, and practice. New York: McGraw-Hill. 
Hoy, W.K. i in. (1990). Organizational health, climate, and effectiveness: A comparative study. Educational Administration Quarterly, 26(3), s. 260-279.

Levine, D.U., Lezotte, L.W. (1990). Unusually effective schools: A review and analysis of research and practice. The National Center for Effective Schools Research and Development, Madison.

Lieberman, A. (1990). Schools as collaborative cultures: Creating the future now. Bristol: Falmer Press.

Loeffelmeier, R. (2009). Erneuerung der Schulkultur - Programm und Praxis in der Weimarer Zeit. Zeitschrift für Pädagogik, 55(3), s. 345-356.

Loukas, A., Murphy, J.L. (2007). Middle school student perceptions of school climate: Examining protective functions on subsequent adjustment problems. Journal of School Psychology”, 45(3) s. 293-309.

Łukasik, J.M. (2010). Klimat pokoju nauczycielskiego. Ruch Pedagogiczny, 5-6, s. 51-59.

Łukasik, J.M., Pikuła, N.G. (2015). The Selected Aspects of School Culture in Teachers' Perception. Pedagogy 2015, 1, s. 78-92. Pobrane z: http://www.azbuki.bg/en/editions/ azbuki/archive/archive2011/doc_download/2197-lukasik-pikula012015

National School Climate Center (2014). Pobrane z: http://www.schoolclimate.org/climate/ http://www.schoolclimate.org/climate/

National School Climate Council (2007). The school climate challenge: Narrowing the gap between school climate research and school climate policy, practice guidelines and teacher education policy. Pobrane z: http://www.schoolclimate.org/climate/documents/ policy/school-climate-challengeweb.pdf

Nowosad, I. (2017). Rozwój i główne nurty badan efektywności szkoły. Studia Edukacyjne, 46, s. $125-152$.

Neuberger, O., Kompa, A. (1987). Wir, die Firma. Der Kult um die Unternehmenskultur. München: Heyne.

Owens, R.G. (2001). Organizational behavior in education: instructional leadership and school reform. Boston: Allyn \& Bacon.

Poole, M.S. (1985). Communication and organization climates. W: R.D. McPhee, P.K. Thompkins (red.), Organizational communication: Traditional themes and new directions (s. 79-108). Beverly Hills: Sage.

Prosser, J. (1999). The Evolution of School Culture Research. W: J. Prosser (red.), School Culture (s. 1-14). London: Paul Chapman Publishing.

Sarason, S. (1971). The culture of the school and the problem of change. Boston: Allyn \& Bacon.

Sarason, S. (1990). The predictable failure of educational reform: Can we change course before it's too late? San Francisco: Jossey-Bass.

Sarason, S. (1996). Revisiting „the culture of the school and the problem of change”. New York: Teachers College Press.

Schoen, L.T., Teddlie, C. (2008). A new model of school culture: a response to a call for conceptual clarity. School Effectiveness and School Improvement, 19(2), s. 129-153.

Schwartz, H., Davis, S. (1981). Matching corporate culture and business strategy. Organizational Dynamics, 10(1), s. 30-48. 
Stoll, L., Myers, K. (1997). No quick fixes: Perspectives on schools in difficulty. Lewes: Falmer Press.

Stoll, L., Fink, D. (1996). Changing our schools. Buckingham: Open University Press.

Stolp, S., Smith, S.C. (1995). Transforming school culture. Stories, symbols, values \& the leader's role. Oregon.

Szczecińska, D. (2010). Kultura organizacyjna efektywnej szkoły. W: I. Nowosad i in. (red.), Jakość życia i jakość szkoły. Wprowadzenie w zagadnienia jakości i efektywności pracy szkoły (s. 143-166). Oficyna Uniwersytetu Zielonogórskiego: Zielona Góra.

Tagiuri, R. (1968). The concept of organizational climate. W: R. Tagiuri, G. Litwin (red.). Organizational climate. Explorations of a concept (s. 11-32). Cambridge: Harvard University Press.

Teddlie, C., Stringfield, S. (1993). Schools make a difference: Lessons learned from a ten-year study of school effects. New York: Teachers College Press.

U.S. Department of Education, Office of Safe and Drug-Free Schools (2007). Mobilizing for evidence-based character education. Washington. Pobrane z: http://www2.ed.gov/ programs/charactered/mobilizing.pdf

Van Houtte, M. (2005). Climate or culture? A plea for conceptual clarity in school effectiveness research. School Effectiveness and School Improvement, 16(1), s.71-89.

Van Houtte, M., Van Maele, D. (2011). The black box revelation: in search of conceptual clarity regarding climate and culture in school effectiveness research. Oxford Review of Education, 37(4), s. 505-524.

Ward, R.E., Burke, M.A. (red.) (2004). Improving Achievement Low Performing School. Key Results of School Leaders. London: Sage Publ.

Wiater, W. (1997). Schulkultur - ein Integrationsbegriff für die Schulpädagogik? W: N. Seibert (red.), Anspruch Schulkultur. Interdisziplinäre Darstellung eines neuzeitlichen Schulpäda-gogischen Begriffs (s. 21-43). Bad Heilbrunn: Klinkhardt. 